\title{
Fluorescence In Situ Hybridization (FISH)
}

National Human Genome Research Institute (NHGRI)

\section{Source}

National Human Genome Research Institute (NHGRI). Fluorescence In Situ Hybridization

$(F I S H)$.

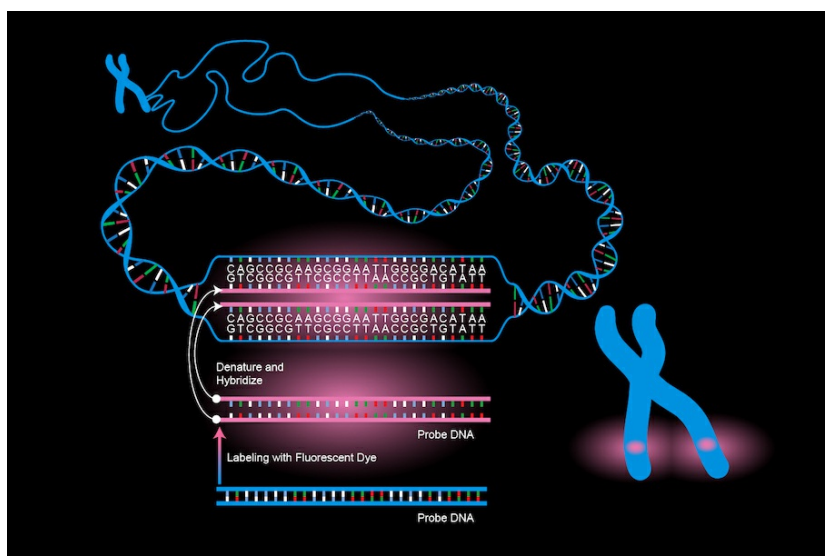

Fluorescence in situ hybridization (FISH) is a laboratory technique for detecting and locating a specific DNA sequence on a chromosome. The technique relies on exposing chromosomes to a small DNA sequence called a probe that has a fluorescent molecule attached to it. The probe sequence binds to its corresponding sequence on the chromosome. 